\title{
DEMO Design using the SYCOMORE System Code: Influence of Technological Constraints on the Reactor Performances
}

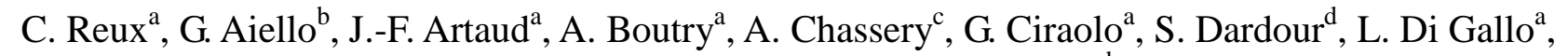
J.-L. Duchateau ${ }^{\mathrm{a}}$, D. Galassi ${ }^{\mathrm{a}, \mathrm{e}}$, P. Hertout ${ }^{\mathrm{a}}$, F. Imbeaux ${ }^{\mathrm{a}}$, J.-C. Jaboulay ${ }^{\mathrm{b}}$, M. Kresina ${ }^{\mathrm{c}}$, P. Magaud ${ }^{\mathrm{a}}$, M.

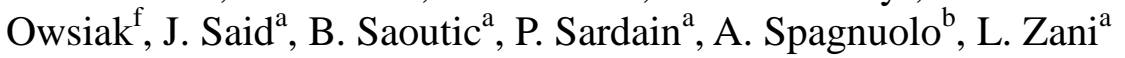

${ }^{a}$ CEA, IRFM, F-13108 Saint-Paul-lez-Durance, France

${ }^{b}$ CEA, DEN, Saclay, DM2S, SERMA, F-91191 Gif-sur-Yvette, France

${ }^{c}$ CEA, DEN/DTN/SMTALIPC F-13108 Saint Paul-lez-Durance, France

${ }^{d}$ CEA, DEN/DER/SESI/LEMS F-13108 Saint Paul-lez-Durance, France

${ }^{e}$ Aix-Marseille Université, CNRS, Centrale Marseille, M2P2 UMR 7340, 13451 Marseille, France

${ }^{f}$ Poznan Supercomputing and Networking Center, IChB PAS, Noskowskiego 12/14,61-704 Poznan, Poland

*Corresponding author: cedric.reux@cea.fr

The next step for fusion energy after the ITER tokamak is the demonstration power plant DEMO. In this framework, system codes are used to address high-level key design issues for the DEMO preconceptual phase. They aim at capturing the interactions between the subsystems of a fusion reactor. SYCOMORE is a modular system code which includes physics and technology models coupled to an optimizer and a sampler in order to explore a large design parameter space. It contains a unique suite of technology-related modules: HCLL blanket including neutronics, thermomechanical and thermohydraulical modelling, magnets including Toroidal Field Coils, Central Solenoid and Poloidal Field coils, with the possibility to explore High Temperature Superconductors domains, power conversion systems including three coolants loops (divertor, blankets and steam turbine) with 4 coolant options, and a tritium cycle module. SYCOMORE has been validated against the ITER design: if target performances of ITER are given to the code as input, the resulting design is correct within $30 \mathrm{~cm}$ margin. Trade-offs studies focused on technology modules will be reported including the influence of some design-driving assumptions on the reactor performances and size: influence of the target tritium breeding ratio on the tokamak size or burn duration, influence of the maximum allowed field on the conductor on the global performances. The importance of the coolant combination on the net electric power output for different reactor classes (low or high fusion power) will also be assessed. Various assumptions made for technological constraints on subsystems (magnets, breeding blankets, tritium cycle) will be explored.

Keywords: DEMO, system code, fusion reactor, breeding blankets, magnets, tritium, power balance

\begin{tabular}{l|l}
\hline Topic Category & DEMO \\
\hline Presentation Preference & $\square$ Oral Presentation $\square$ Poster Presentation \\
\hline
\end{tabular}

